\title{
Waste Management Options for Long-Duration Space Missions: When to Reject, Reuse, or Recycle
}

\author{
Diane L. Linne, ${ }^{1}$ Bryan A. Palaszewski, ${ }^{2}$ Suleyman Gokoglu, ${ }^{3}$ and Christopher A. Gallo ${ }^{4}$ \\ NASA Glenn Research Center, Cleveland, OH, 44133, USA \\ Ramaswamy Balasubramaniam, ${ }^{5}$ and Uday G. Hegde ${ }^{6}$ \\ National Center for Space Exploration Research, Cleveland, OH, 44133, USA
}

\begin{abstract}
The amount of waste generated on long-duration space missions away from Earth orbit creates the daunting challenge of how to manage the waste through reuse, rejection, or recycle. The option to merely dispose of the solid waste through an airlock to space was studied for both Earth-moon libration point missions and crewed Mars missions. Although the unique dynamic characteristics of an orbit around $L 2$ might allow some discarded waste to intersect the lunar surface before re-impacting the spacecraft, the large amount of waste needed to be managed and potential hazards associated with volatiles recondensing on the spacecraft surfaces make this option problematic. A second option evaluated is to process the waste into useful gases to be either vented to space or used in various propulsion systems. These propellants could then be used to provide the yearly station-keeping needs at an L2 orbit, or if processed into oxygen and methane propellants, could be used to augment science exploration by enabling lunar mini landers to the far side of the moon.
\end{abstract}

\begin{tabular}{|c|c|}
\hline & Nomencl \\
\hline A & $=$ surface flux coefficient, $\mathrm{kg} / \mathrm{m}^{2}-\mathrm{s}-\mathrm{K}^{3}$ \\
\hline ECLSS & $=$ environmental closed loop life support system \\
\hline $\mathrm{j}$ & $=$ surface flux, $\mathrm{kg} / \mathrm{m}^{2}-\mathrm{s}$ \\
\hline $\mathrm{k}$ & $=$ thermal conductivity, $\mathrm{W} / \mathrm{m}-\mathrm{K}$ \\
\hline LEO & $=$ Low Earth Orbit \\
\hline L2 & $=$ Earth-Moon libration point \\
\hline $\mathrm{L}_{\mathrm{f}}$ & $=$ Latent heat of freezing, $\mathrm{J} / \mathrm{kg}$ \\
\hline $\mathrm{L}_{\mathrm{s}}$ & $=$ Latent heat of sublimation, $\mathrm{J} / \mathrm{kg}$ \\
\hline $\mathrm{R}$ & $=$ radius of drop or waste package, $\mathrm{m}$ \\
\hline $\mathrm{RCS}$ & $=$ reaction control system \\
\hline TMI & $=$ trans-Mars insertion \\
\hline $\mathrm{T}_{\mathrm{a}}$ & $=$ ambient temperature, $\mathrm{K}$ \\
\hline $\mathrm{T}_{\mathrm{f}}$ & $=$ freeze front temperature, $\mathrm{K}$ \\
\hline $\mathrm{T}_{\mathrm{s}}$ & $=$ surface temperature, $\mathrm{K}$ \\
\hline $\mathrm{t}$ & $=$ non-dimensional time \\
\hline$t_{f}$ & $=$ time to freezing, $\mathrm{s}$ \\
\hline$\varepsilon$ & $=$ fraction water content \\
\hline$\delta$ & $=$ non-dimensional freeze front radius \\
\hline$\rho$ & $=$ density, $\mathrm{kg} / \mathrm{m}^{3}$ \\
\hline$\lambda$ & $=$ non-dimensional thermal coefficient \\
\hline
\end{tabular}

\footnotetext{
${ }^{1}$ Senior Research Engineer, Power and In-Space Propulsion Division, MS 301-3, AIAA Associate Fellow.

${ }^{2}$ Leader of Advanced Fuels, Combustion Branch, MS 5-10, AIAA Associate Fellow.

${ }^{3}$ Senior Scientist, Department Name, MS 77-5.

${ }^{4}$ Mechanical Engineer, Systems Integration Branch, MS 86-1.

${ }^{5}$ Senior Scientist, MS 110-3.

${ }^{6}$ Senior Scientist, MS 110-3, AIAA Associate Fellow.

American Institute of Aeronautics and Astronautics
} 


\section{Introduction}

$\mathrm{W}$ HILE much focus for long-duration space missions is placed on ensuring the crew have the necessary supplies and equipment to survive and thrive, of equal importance is the challenge of managing the waste that is produced. Waste material generated daily includes crew biological products (carbon dioxide, water, human liquid and solid waste) and solid and liquid wastes such as food remnants, clothing, packaging, etc. Currently, the crew on the International Space Station hand-compact the waste material, wrap it in duct tape, and store it until the next supply vehicle arrives. The waste is then packed into the emptied supply vehicle, which burns up in the Earth's atmosphere. For missions farther away from Earth, such as at an Earth-moon Libration point or on a transit to Mars, this option is not feasible, and other solutions must be found.

This paper presents several options for waste management for long-duration missions, including disposing solid waste out into open space, partially processing into mixed gases before venting, and fully processing into highquality propellant gases that can then be used to augment the mission. Challenges and potential ejection methods for disposing of solid trash were analyzed, and potential propulsion and mission performance benefits for using wasteproduced propellants in a resistojet thruster are presented.

\section{Vehicle and Mission Descriptions}

In order to provide a baseline for evaluation of waste management concepts, two missions and their associated vehicles were defined. The first mission was a Gateway mission concept, where a vehicle and crew are positioned at the Earth-moon L2 libration point for scientific study of the moon. The second mission was a Mars exploration mission.

\section{A. Gateway Mission}

The Gateway mission was still being defined by NASA architecture teams at the time this study was conducted, but some general information relevant to this analysis was available. As envisioned, the Gateway mission would consist of a core module with a habitable volume for four crew members. It would be deployed to L2 without crew using solar electric propulsion powered by large solar arrays that also provide module power while at L2. Once the core module is established at the libration point, a crew module such as Orion will deliver the four crew members, carrying only enough food and supplies for the trip to and from L2. An open-loop ECLSS system collects $\mathrm{CO}_{2}$ and adsorbs crew humidity and vents to vacuum. A separate logistics module brings supplies to support the mission. At the time of this study, there was no definition of how the logistics module gets to the L2 location, or where it goes after delivering the supplies. In Phase II, an 'augmentation module' would be added to the assets at L2, providing equipment for longer duration stays such as closed-loop ECLSS and exercise equipment.

For the Phase I mission scenario, the core module weighs $28,750 \mathrm{~kg} .{ }^{1}$. The logistics module delivers $2700 \mathrm{~kg}$ of cargo supplies, for a mission length of 24 to 90 days. The core module remains at L2 for long unoccupied periods when the crew returns to Earth. For the Phase II missions, the augmentation module is added to the core module for a total mass of $45,570 \mathrm{~kg}$. Mission length is increased to 90 to 180 days.

\section{B. Mars Mission}

For the Mars mission, the architecture described in the Mars Design Reference Architecture 5.0 documents was used as our baseline. ${ }^{2}$ In DRA 5, nuclear thermal rocket propulsion was assumed, using hydrogen drop tanks that are detached after the trans-Mars injection burn (outbound) and before the trans-Earth injection burn (inbound). A storable propellant reaction control system (RCS) is used for LEO 'mating' of vehicle components as well as midcourse corrections. Burn times include 57.8 minutes for the trans-Mars injection, 16 minutes for the Mars orbit insertion, and 10.7 minutes for the transEarth injection. Table I lists the major vehicle elements, their initial mass in LEO, and their mass in transit to Mars. Some of the masses listed during transit to Mars are estimates based on values Table I. Mars mission elements.

\begin{tabular}{|l|c|c|c|}
\hline \multicolumn{1}{|c|}{ Vehicle Element } & $\begin{array}{c}\text { Initial Mass in } \\
\text { LEO, } \\
\text { metric tons }\end{array}$ & $\begin{array}{c}\text { Mission } \\
\text { Phase }\end{array}$ & $\begin{array}{c}\text { Mass in transit } \\
\text { to Mars, } \\
\text { metric tons }\end{array}$ \\
\hline NTR “Core" Stage & 106.2 & all & $72.1^{*}$ \\
In-Line LH2 Tank & 91.4 & TMI & 0 \\
Long Saddle Truss \& LH2 Drop Tank & 96.0 & TMI, MOI & $61.3^{*}$ \\
Payload Elements & 62.8 & all & 62.8 \\
\hline TOTAL & $\mathbf{3 5 6}$ & & $\mathbf{1 9 6}$ \\
\hline
\end{tabular}

* Estimate based on values given in Ref. 2 for engine burn-time per mission phase, In-Line LH2 tank dropped after TMI, and assumption that remaining TMI propellant split between core and drop tank. given in Ref. 2 for engine burn-time per 
mission phase, and the assumption that the in-line LH2 tank is dropped after the trans-Mars injection (TMI) burn and the remaining TMI propellant is split between the core and drop tank.

\section{Waste Model for Crewed Missions}

A detailed model of the waste generated during crewed missions has been developed based on study of the Space Shuttle and the International Space Station waste products, and projections of future exploration vehicles. Items in the waste model include clothing, paper, foam packaging, wipes and other personal hygiene items, EVA supplies, and human wastes. In addition to identifying the amount of waste per day in each category, the elemental composition of each waste type has also been defined. ${ }^{3}$ Table II shows some of the waste quantities by type, along with the total amount generated during a Gateway mission

Table II. Mission waste summary.

\begin{tabular}{|l|c|cc|c|}
\hline & & \multicolumn{2}{|c|}{ Gateway Mission } & $\begin{array}{c}\text { Mars one-way } \\
\text { transit }\end{array}$ \\
\hline \multicolumn{1}{|c|}{ Waste Description } & $\begin{array}{c}\text { Waste } \\
\text { Amount } \\
\text { (kg/cm-d) }\end{array}$ & $\begin{array}{c}\text { Phase I } \\
\text { Total Mass (kg) }\end{array}$ & $\begin{array}{c}\text { Phase II } \\
\text { Total Mass (kg) }\end{array}$ & $\begin{array}{c}\text { Mars DRA 5.0 } \\
\text { Total Mass (kg) }\end{array}$ \\
\hline Clothing & 0.160 & $15-58$ & $58-115$ & 173 \\
Paper \& Office Supplies & 0.007 & $1-2$ & $2-5$ & 7 \\
Wipes/Tissues & 0.137 & $13-49$ & $49-99$ & 148 \\
Towels and Hygiene & 0.098 & $9-35$ & $35-71$ & 106 \\
Foam Packaging for Launch & 0.040 & $4-14$ & $14-29$ & 43 \\
Other Crew Supplies & 0.037 & $4-13$ & $13-27$ & 40 \\
Food \& Packaging & 0.352 & $24-127$ & $127-253$ & 380 \\
EVA Supplies & 0.010 & $1-4$ & $4-7$ & 11 \\
Human Wastes & 0.449 & $43-162$ & $162-324$ & 485 \\
Waste Recovery/Mgt System & 0.162 & $16-58$ & $58-116$ & 174 \\
TOTAL & $\mathbf{1 . 4 5}$ & $\mathbf{1 3 9 - 5 2 3}$ & $\mathbf{5 2 3 - 1 0 4 6}$ & $\mathbf{1 5 6 9}$ \\
\hline
\end{tabular}
an Earth-to-Mars transit mission.

\section{Option 1: Dispose of Raw Waste Via Airlock}

One proposed option to manage waste is to dispose of it via an airlock into space. Before the feasibility of this option could be evaluated, several questions needed to be addressed: the behavior of waste (especially with a highliquid content) when exposed to a sudden vacuum, the trajectory of the waste after leaving the spacecraft, and possible mechanical means for ejecting the waste.

\section{A. Behavior of Waste When Exposed to a Vacuum}

On the International Space Station waste is hand-compressed, wrapped in tape, and placed in a stowage bag until transferred to the empty supply ship for disposal. Because of the size and shape of the individual waste nodules, they are often referred to as a trash 'football.' Previous experience with the shuttle and ISS shows that water can leak out

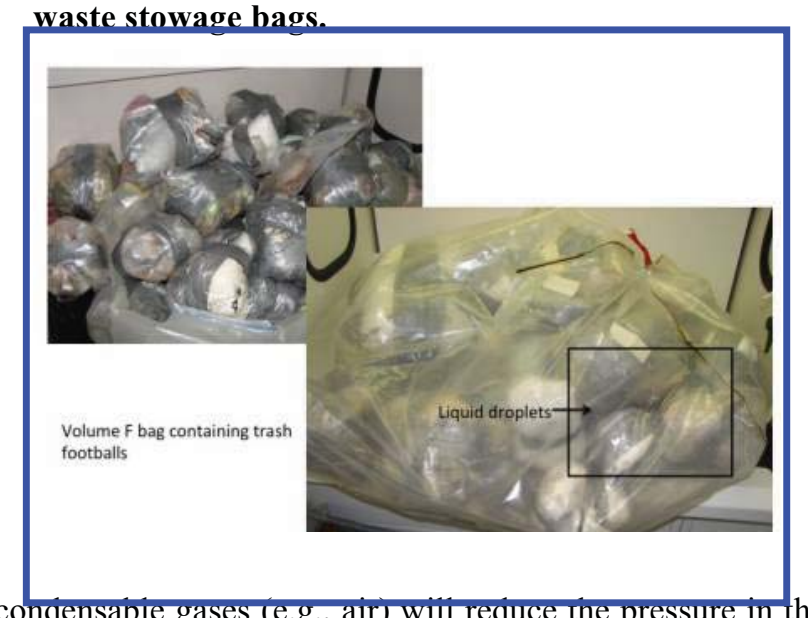

Figure 1. ISS (top) trash footballs and (bottom) waste stowage hags. of a football even after it is wrapped tightly in tape. Figure 1 shows a pile of these trash footballs on the ISS and a stowage bag filled with footballs with some liquid droplets on the inside surface of the bag.

Fluids inside of the trash football may leak outside as either liquid or gas. For example, if the football is not well packed, leaking liquid may adhere to the outside surface of the football. Volatiles and gases may also escape. As vacuum is drawn in the airlock some of the liquid (water or volatiles) will evaporate. The remaining liquid will freeze due to cooling associated with the evaporation. The escaping water vapor/volatiles may recondense on the airlock surfaces. Even if the trash football is well taped so that there is no liquid escaping it is likely that the stowage bags will have some permeability to gas/water vapor transport. Then, as a vacuum is pulled in the airlock, escaping nontrash temperature since there is no latent heat loss. On the other hand, liquid water or volatiles in the football, will 
also feel the vacuum resulting in some evaporation and escape of vapor from the trash bag. Apart from reducing the pressure in the bag, the evaporating water can significantly cool and freeze the remaining water in the trash.

The behavior of the waste when exposed to vacuum may thus be understood by analyzing the evaporation and freezing of liquid water when exposed to vacuum. In order to do so the choice of geometric configuration for the liquid water has to be made. If the water is free, i.e., not trapped in the trash (e.g., water droplets as seen in Fig. 1) a spherical configuration is appropriate. Water may also be trapped in mm-size pores to $\mathrm{cm}$-size pockets in the trash. In these cases, water may or may not be directly exposed to vacuum depending upon the pore/pocket size and structure. If the trash is loosely packed inside the football, water can evaporate from all exposed surfaces within the bulk of the trash. On the other hand, if the trash is packed tightly, water movement and evaporation within the trash will be hindered. The rate of water loss will then be controlled by the evaporation rate from the outside surface of the trash football. Thus, freezing of individual droplets of water of small size and that of water within the trash football due to evaporation from its surface will likely bracket the range of timescales for freezing. To analyze these cases the assumption of a spherical configuration will be made; however, it will be recognized that the water content in this sphere is a fraction $\varepsilon$ which is less than or equal to one (one implying that the entire sphere is water as in the case of a water droplet). For simplicity, physical properties such as density and thermal conductivity of the trash and water are assumed to be the same.

By considering an energy balance for the surface layer of water it may be shown that a thin $(\sim 10$ microns $)$ icy crust forms almost immediately ( $\sim 1$ millisecond) upon exposure to vacuum as latent heat supplied to the resulting surface flux of water is lost by the surface layer. The surface flux, $\mathrm{j}$ in $\mathrm{kg} /\left(\mathrm{m}^{2} \mathrm{~s}\right)$, of water vapor upon exposure to vacuum is provided by previous analyses ${ }^{4,5}$ as a function of the surface temperature, $T_{s}$, and is found during the present analysis to be well approximated by a cubic fit

$$
j=A\left(T_{s}-T_{a}\right)^{3}
$$

where $\mathrm{Ta}$ is the ambient temperature which is assumed to be below the freezing temperature. For example if $\mathrm{T}_{\mathrm{a}}$ is $220 \mathrm{~K}, \mathrm{~A}=4.533 \mathrm{x}$ $10^{-6} \mathrm{~kg} /\left(\mathrm{m}^{2} \mathrm{~s} \mathrm{~K}\right)^{3}$.

Following the formation of the icy surface layer, a freeze front propagates much more slowly through the bulk as further sublimation occurs. With an outer zone of ice, the water-trash spherical geometry may then be represented by Fig. 2 with $T_{\mathrm{f}}$ being the temperature of the freeze front.

The following quantities are defined:

Figure 2. Representative water-trash spherical geometry.

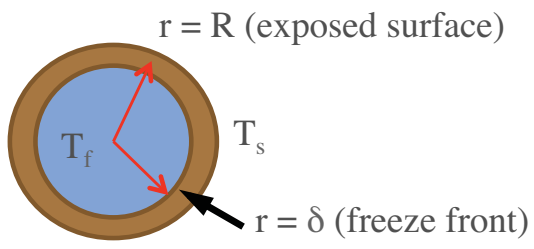

$\delta=$ dimensional freeze front radius/R i.e., the non-dimensional freeze front location

$\mathrm{t}=$ dimensional time $/ \tau$, i.e., non-dimensional time

and the time scale $\tau$ is defined by:

$$
\tau=\varepsilon \rho L_{f} R /\left(3 L_{s} A\left(T_{f}-T_{a}\right)^{3}\right)
$$

where $\rho$ is density of the water-trash mix, $\mathrm{L}_{\mathrm{f}}$ is the latent heat of freezing, $\mathrm{L}_{\mathrm{s}}$ is the latent heat of sublimation and $\mathrm{R}$ is the radius of the droplet or trash football.

With these definitions, equations for mass balance (i.e., water vapor loss) and energy balance (i.e., cooling of trash due to latent heat loss of departing vapor) may be written as:

$$
-3 \delta^{2} d \delta / d t=[1+(3 / \lambda) \delta(1-\delta) d \delta / d t]^{3}
$$

and

$$
\left(T_{s}-T_{a}\right) /\left(T_{f}-T_{a}\right)=1+(3 / \lambda) \delta(1-\delta) d \delta / d t
$$


In obtaining these equations, the temperature distribution from the surface of the sphere to the freeze front location is assumed to be governed by conduction. The parameter $\lambda$ is given by

$$
\lambda=k /\left(L_{s} A R\left(T_{f}-T_{a}\right)^{2}\right)
$$

where $\mathrm{k}$ is the thermal conductivity of the water-trash mixture. The initial condition on $\delta$ is that the freeze front is located at the outer surface, i.e.,

$$
\delta(t=0)=1
$$

The solutions have to be found numerically.

A sample solution for the freeze front location is plotted in Fig. 3 for the case of a $20 \mathrm{~cm}$ trash football with $\varepsilon=0.164$ and $\mathrm{k}=0.2 \mathrm{~W} /(\mathrm{m} \mathrm{K})$ corresponding to a typical water fraction and thermal conductivity for mechanically compacted trash. Density and latent heats used are those for water. The parameter $\tau / \lambda$ is related to the time $t_{f}$ for which the water in the trash football is fully frozen. $t_{f}$ is numerically determined to be approximately 3.4 hours in this case. On the other hand, a small water droplet of $3-\mathrm{mm}$ diameter is found to be fully frozen in about 7 seconds. We have included a sensible heat contribution in the calculations by adding it to the latent heat of freezing.

Because the latent heats are significantly higher than the sensible heats for cases of interest, the fraction of available water evaporated to freeze all of the water in the trush will he similar for these cases Evaporation of ahout 20 percent of the available water is sufficient to freeze all of the water in the sample.

\section{B. Orbital Mechanics at L2 Affecting Waste Disposal}

The L2 libration point is a semi-stable location in the Earth-moon gravitational system located approximately $65,000 \mathrm{~km}$ away from the center of the Moon, is on the opposite side of the Moon from the Earth, and has full visibility of the far side of the moon. However, any object at L2 is really in an orbit around the theoretical L2 gravitational 'balance' point. The recent ARTEMIS mission to the moon used the L1 and L2 points to study the Sun-Moon interactions. Figure 4 shows the unique kidney-shaped orbits of the two ARTEMIS probes. The maximum X, Y, and Z amplitude of the ARTEMIS P1 probe around the L2 point was approximately 32,700, 63,500 , and $35,200 \mathrm{~km}$, respectively. ${ }^{6}$ Methodologies to calculate the delta-velocity required for orbit maintenance result in greatly different values; multiple sources were reviewed with results ranging from $5 \mathrm{~m} / \mathrm{s}$ to hundreds of m/s. Table III lists examples of the different types of maintenance plans that can be used to maintain a stable orbit at the L2 point that were evaluated prior to the ARTEMIS mission. ${ }^{6}$ The ARTEMIS mission selected to perform maintenance burns at every crossing of the X-Z plane, with a predicted average yearly delta-V of about $12.25 \mathrm{~m} / \mathrm{s}$.

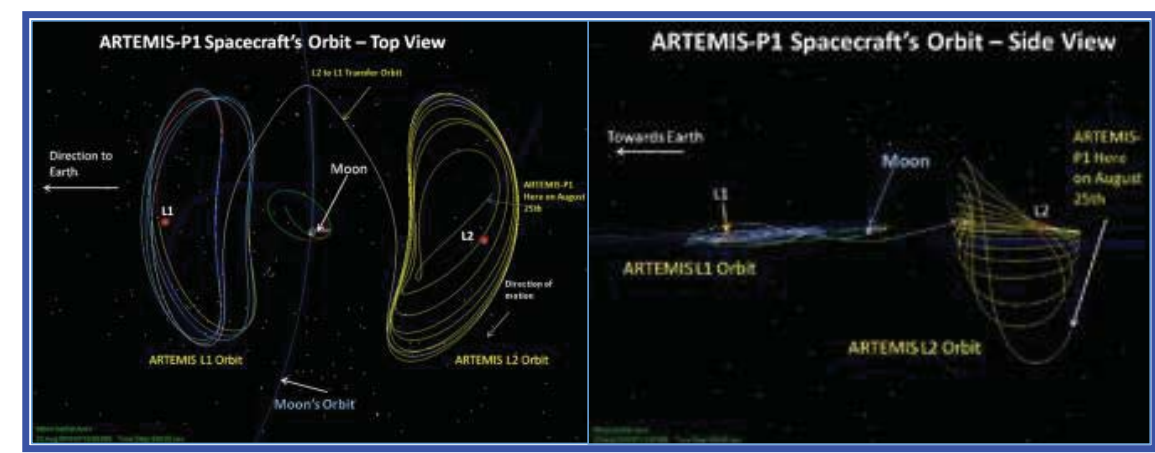

Figure 4. Pictorial representation of L2 orbit (credit: NASA/Goddard).

5

American Institute of Aeronautics and Astronautics The actual orbit maintenance delta-V required on the mission was less than $10 \mathrm{~m} / \mathrm{s}$ on a yearly basis.

Total mission delta- $\mathrm{V}$ values for ARTEMIS are between 220 and $425 \mathrm{~m} / \mathrm{s}$. These include a wide range of maneuvers (for deep space maneuvers, lunar orbit adjustments, etc.), however, the values here are for a specific science mission and

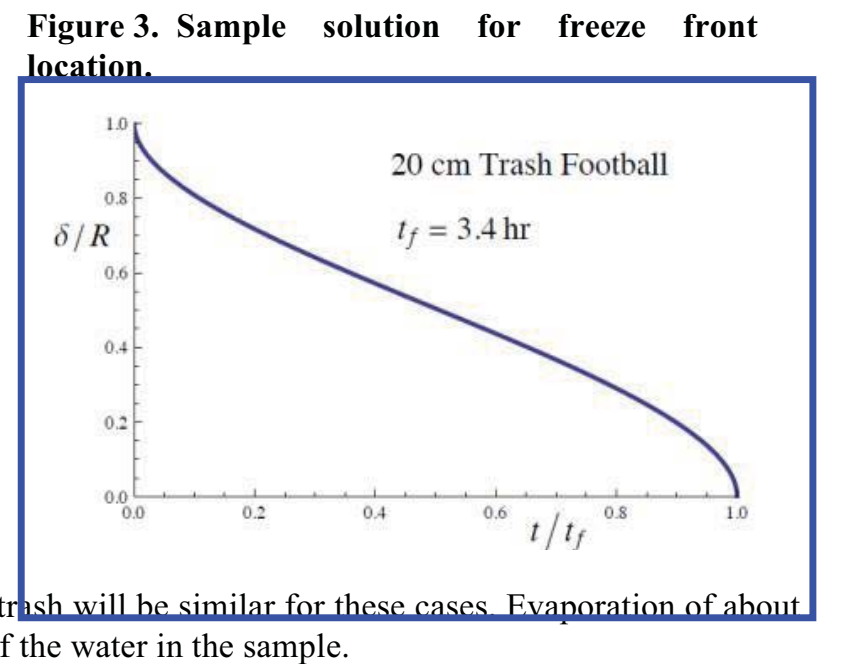


do not reflect the typical maneuvers for a crewed libration point spacecraft. Also, they do not include the propulsive delta-V to place the vehicle on the trajectory toward the Moon.

Historically, Earth-Moon libration points were studied to offer wider access to the lunar surface. ${ }^{7}$ The mission strategy was developed to allow a carrier spacecraft and lander(s) to arrive at the libration point, and then place the lander(s) on trajectories that allow access to the lunar polar regions as well as the equatorial sites. The delta- $\mathrm{V}$ to enter or exit the libration points was estimated to be $1,077 \mathrm{~m} / \mathrm{s}$ for the $\mathrm{L} 2$ point and $688 \mathrm{~m} / \mathrm{s}$ for the L1 point. An additional landing delta- $\mathrm{V}$ is required and is estimated to be $2,800 \mathrm{~m} / \mathrm{s}$. In comparison, the delta- $\mathrm{V}$ required for entering low lunar orbit is approximately $900 \mathrm{~m} / \mathrm{s}$. A nominal landing from low lunar orbit or an ascent back to lunar orbit requires approximately $2,000 \mathrm{~m} / \mathrm{s} .{ }^{8}$ Though the delta- $\mathrm{V}$ for entering the libration point and landing are higher than the values for entering low lunar orbit and landing from the low orbit, using the libration point as a site for operations is preferred if multiple diverse landing sites must be accessed.

For human Mars missions, the delta- $\mathrm{V}$ needed for midcourse correction maneuvers is modest: about 2 to $25 \mathrm{~m} / \mathrm{s}$. A Mars entry corridor maneuver is approximately $25 \mathrm{~m} / \mathrm{s}$. Though these delta-V values are small, the large mass of the Mars Transfer Vehicle and lander results in total propellant mass for these maneuvers of Table III. Possible L2 orbit maintenance plans (Ref. 6).

\begin{tabular}{|c|c|c|c|c|c|}
\hline Mancuver Location & $\begin{array}{c}\text { No. of } \\
\text { Maneuvers }\end{array}$ & $\begin{array}{l}\text { Avg } \Delta v \text { per } \\
\text { Maneuver } \\
(\mathrm{m} / \mathrm{s})\end{array}$ & $\begin{array}{l}\text { Std Dev } \\
(\mathrm{m} / \mathrm{s})\end{array}$ & $\begin{array}{c}\text { Avg } \Delta v \\
\text { per Year } \\
(\mathrm{m} / \mathrm{s})\end{array}$ & $\begin{array}{c}\text { Avg Time } \\
\text { Between } \\
\text { Maneuver (days) }\end{array}$ \\
\hline $\begin{array}{l}\mathrm{X}-\mathrm{Z} \text { plane, every } \\
\text { crossing }\end{array}$ & 15 & 0.28 & 0.78 & 12.27 & 7.3 \\
\hline $\begin{array}{c}\mathrm{X}-\mathrm{Z} \text { plane, once per } \\
\text { orbit }\end{array}$ & 7 & 4.88 & 7.07 & 106.51 & 15.2 \\
\hline $\begin{array}{l}\text { Max Y-Amp Every } \\
\text { crossing }\end{array}$ & 15 & 0.42 & .95 & 18.13 & 7.3 \\
\hline $\begin{array}{c}\text { Max Y-Amp Once per } \\
\text { orbit }\end{array}$ & 7 & 5.46 & 6.98 & 110.91 & 14.9 \\
\hline $\begin{array}{c}4 \text { Pts } / \text { Rev } \\
(\sim 3.8 \text { days })\end{array}$ & 33 & 0.15 & 0.33 & 13.72 & 3.8 \\
\hline
\end{tabular}
thousands of kilograms for a vehicle mass of several hundred metric tonnes.

\section{Mechanical Options for Waste Disposal}

Two approaches were considered for physically disposing of the waste footballs: a low-velocity and a highvelocity method.

For low-velocity disposal, little or no velocity is imparted to the waste football, and it is simply allowed to 'float away' from the spacecraft. One possible method to achieve a low-velocity disposal is using a device similar to the Japan Experiment Module (JEM) Small Satellite Orbital Deployer (J-SSOD) already demonstrated on the International Space Station. ${ }^{9}$ This device is used to deploy CubeSats in the 10 to $50 \mathrm{~cm}^{3}$ class. The deployment velocity is less than $0.10 \mathrm{~m} / \mathrm{s}$ with an accuracy of \pm 5 degrees. In the J-SSOD, up to three CubeSats are loaded into a spring-loaded launcher. Two launchers are mounted on a slider plate that enters the airlock. After airlock depressurization, the plate is extended into space, where an arm grabs the plate and moves it away from the ISS before launch. The J-SSOD currently takes 3 hours to depressurize the airlock. While the airlock depressurization time is likely based on the pump speed that is used to reclaim the air and could be improved with a change in pumps, we have used this time in an initial assessment of how this method could be used to dispose of waste in a Gateway or Mars mission. Table $\mathrm{V}$ lists the total waste mass by mission type for the range of mission durations and number of crew discussed in section II above. Assuming the wet waste can be hand-compressed into oblong-shaped portions approximately $10 \mathrm{~cm}$ by $25 \mathrm{~cm}$ long, each football has a volume of approximately $2000 \mathrm{~cm}^{3}(2 \mathrm{~L})$. Based on examination of returned waste samples, the density of the hand-compressed football is approximately $160 \mathrm{~kg} / \mathrm{m}^{3}$, which results in about $300 \mathrm{gm}$ per football. Two such footballs can fit in each of two launchers of the size of the JSSOD launchers. Table IV shows the number of launches and total hours required for each mission class. The last column also lists the total mission duration for comparison, showing that if this method is selected a crewmember could spend over half of the mission hours handling the disposal of waste. While many adjustments to the assumptions used here can be made to reduce this extremely large time-demand, it is clear that disposing of waste in this manner is not a trivial endeavor.

Table IV. Total waste packages generated on long-duration missions.

\begin{tabular}{|l|c|c|c|c|c|c|}
\hline \multicolumn{1}{|c|}{ Mission Type } & $\begin{array}{c}\text { Total Waste } \\
\text { Mass, kg }\end{array}$ & $\begin{array}{c}\text { Total Waste } \\
\text { Volume, m3 }\end{array}$ & \# of 'Footballs' & \# of Launches & Total hrs & $\begin{array}{c}\text { Total Mission } \\
\text { Duration, hrs }\end{array}$ \\
\hline Gateway Phase I & $140-525$ & $0.9-3.3$ & $445-1665$ & $111-416$ & $335-1250$ & $576-2160$ \\
\hline Gateway Phase II & $525-1050$ & $3.3-6.5$ & $1665-3330$ & $416-832$ & $1250-2500$ & $2160-4320$ \\
\hline Mars & $1240-1570$ & $7.7-9.8$ & $3940-4995$ & $985-1249$ & $2950-3750$ & $4320-5112$ \\
\hline
\end{tabular}


In addition to the large time-demand, the low velocity disposal approach also introduces the potential risk of some of the waste footballs remaining at or near the spacecraft, especially in the unique dynamic environment of the L2 location. While recent analysis performed at the NASA Johnson Space Center has indicated that even a small delta-V imparted to trash at the proper point in the L2 orbit may result in the trash 'intersection' with the lunar surface, this will not always occur within a single orbit, leaving the potential for a very dangerous impact between the waste object (now frozen) and the spacecraft.

To avoid any situation where the waste footballs remain close enough to the spacecraft to possibly re-impact, methods for high-velocity disposal were evaluated. One possible method would be an electromagnetic launcher such as have been employed on aircraft carriers. However, although these devices can develop exit velocities from 270 $\mathrm{m} / \mathrm{s}$ (mag-lifter) to $8500 \mathrm{~m} / \mathrm{s}$ (gas gun), they are large and power-intensive. In addition, they usually require long acceleration paths and deliver high accelerations, making it difficult to integrate into a traditional spacecraft design. A second method to ensure the waste football leaves the vicinity of the spacecraft is to provide it with some means of propulsion. For example, Ref. 10 describes small CubeSats powered by solar sails that can escape the Earth's orbit through a spiral trajectory over the course of more than 7 months. Assuming that half of the $10-\mathrm{kg}$ mass of the solar-sail CubeSat is dedicated to solar panels, attitude control, and other components necessary for propulsion, the other $5-\mathrm{kg}$ is then presumably left for payload which could be a waste football. Of course, throwing away $5 \mathrm{~kg}$ of valuable propulsion components for every $5-\mathrm{kg}$ of waste removed is highly unlikely to prove to be a cost-effective option for waste management.

In summary, while exposing the waste to a sudden vacuum of space would not result in any large overpressurizations of internal water causing explosive rupturing of the wrapped footballs, 20 percent of the water will sublimate over a longer period of time and could re-condense on the spacecraft surfaces or be ingested into the airlock pump. High-velocity disposal methods are not feasible from a size, mass, power, and/or cost stand-point. Noor low-velocity disposals are feasible, although more analysis is required to ensure that the waste footballs will not re-impact the spacecraft due to the unique orbital dynamics that exist at the L2 location. Also, extensive additional evaluation of this option and spacecraft design would need to be performed to reduce the amount of time required to dispose of the large number of waste footballs that will be generated during these missions.

\section{Option 2: Convert Waste into Gas for Use or Disposal}

An alternative option to manage waste is to process it into gases that can either be vented to space or stored and used during the mission. Several methods for processing the waste into gas are being evaluated, including pyrolysis, gasification, incineration, steam reforming, ozone oxidation, and catalytic wet air oxidation. ${ }^{11}$ While these processes will result in some variation in the product gases, information on the steam reforming process was used in this analysis as a good representation of expected product. With all of the processing methods, there is an option to process the waste in a primary reactor to produce mixed gases consisting primarily of carbon monoxide, carbon dioxide, methane, and hydrogen, or to include a secondary reactors and gas/liquid processing components to convert all the gases to high-quality propellants, typically oxygen and methane. Table $\mathrm{V}$ lists the product mix for each option if processing the wastes mixture listed in Table II, the potential gas generated per crew member per day that could be used for propulsion, and the total propellant mass that could be generated during the various missions Table V. Waste processing potential products.

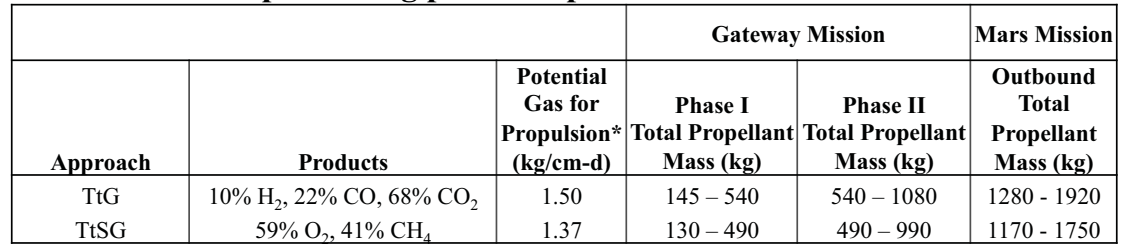

*TtSG requires $0.15 \mathrm{~kg} / \mathrm{cm}$-day make-up water to provide sufficient oxygen to drive reformer reaction;

$\mathrm{TtG}$ requires $0.28 \mathrm{~kg} / \mathrm{cm}$-day make-up water described above.

\section{A. Mass Savings in LEO}

Table II shows that up to $490 \mathrm{~kg}$ of oxygen/methane propellant can be made at the L2 mission site during a Phase I mission, and up to $990 \mathrm{~kg}$ during a Phase II mission. The full benefit of having this propellant resource available at the mission site must also include the propellant and tank mass that is required in low Earth orbit (LEO) to push this amount of propellant out to L2. This type of assessment is often referred to as the gear ratio, which is a measure of how many $\mathrm{kg}$ are needed at your starting location (LEO) for each $\mathrm{kg}$ you need at your mission location 
(L2). Using a typical gear ratio of 4.3 for transfer from LEO to lunar orbit assuming hydrogen/oxygen propulsion $(425 \mathrm{sec}$ specific impulse) and a structural mass fraction of $25 \%$ of propellant mass, the gear ratio from LEO to L2 was calculated for both a Table VI. Benefit analysis for processing waste during L2 missions.

\begin{tabular}{|c|c|c|c|c|c|}
\hline \multicolumn{2}{|c|}{} & \multicolumn{2}{c|}{ Gateway Mission } & \\
\hline $\begin{array}{c}\text { Delivery } \\
\text { Method }\end{array}$ & Isp, sec & Gear Ratio & $\begin{array}{c}\text { Max Phase I } \\
\text { Propellant Mass per } \\
\text { mission (kg) }\end{array}$ & $\begin{array}{c}\text { Max Phase II } \\
\text { Propellant Mass per } \\
\text { mission (kg) }\end{array}$ & $\begin{array}{c}\text { LEO Mass } \\
\text { Savings (kg) }\end{array}$ \\
\hline Chemical & 425 & 3.34 & 490 & 990 & $1635-3300$ \\
SEP & 1500 & 1.35 & 490 & 990 & $660-1340$ \\
\hline
\end{tabular}

chemical transfer vehicle and a solar electric propulsion vehicle (SEP). For this analysis, a delta-V of $4040 \mathrm{~m} / \mathrm{s}$ was assumed for LEO to lunar orbit, and $3430 \mathrm{~m} / \mathrm{s}$ for LEO to L2. Table VI summarizes this benefits analysis, and shows that the $990 \mathrm{~kg}$ of propellant for a Phase II mission can save $3300 \mathrm{~kg}$ of mass in LEO if using a chemical transfer vehicle, and $1340 \mathrm{~kg}$ of mass in LEO if using an electric propulsion vehicle.

\section{B. Performance Potential}

If the waste processing option is selected that stops after the primary reactor with a mixture of gases, these can still be used for low thrust propulsion in a cold-gas thruster or a resistojet. For both of these engines, the

Figure 5. Low-thrust propulsion performance for gases of varying molecular weight.

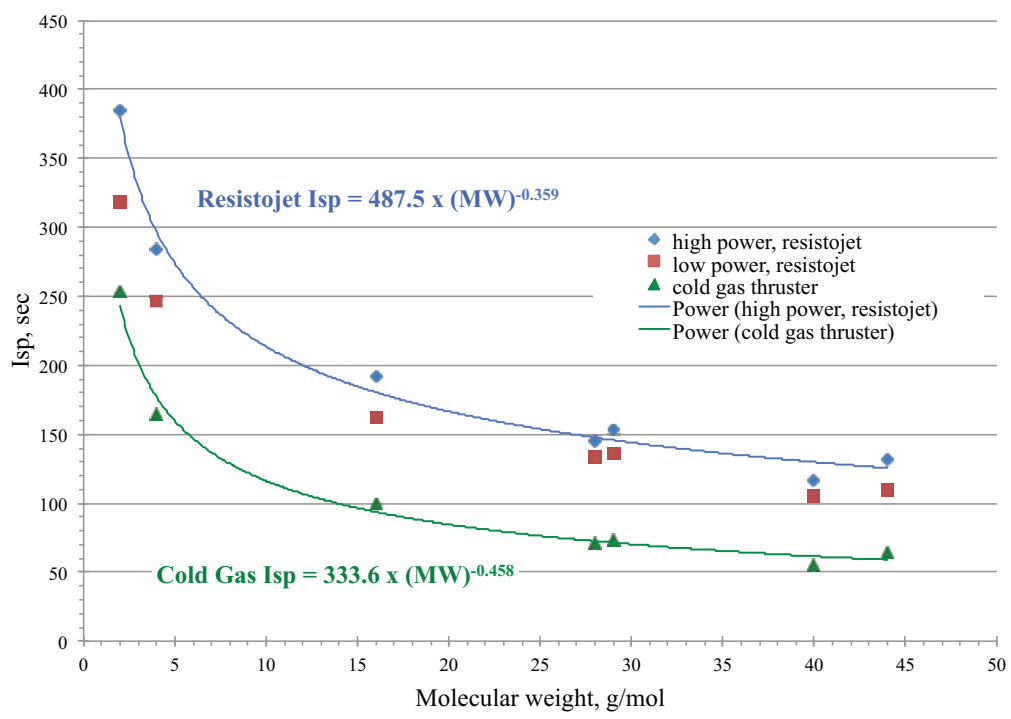

performance is a function of the propellant molecular weight, as shown in Fig. 5. ${ }^{12}$ The average molecular weight of the gases produced from the steam reforming is $36.3 \mathrm{gm} / \mathrm{mole}$, resulting in a resistojet specific impulse of $134.3 \mathrm{sec}$ and a coldgas specific impulse of $64.4 \mathrm{sec}$.

If secondary reactors are included to take the waste processing all the way to oxygen and methane, the mass ratio produced is approximately 1.5 to 1. For a small oxygen/methane rocket engine operating at a more optimal mixture ratio of 3 to 1 , a conservative specific impulse of $300 \mathrm{sec}$ is a good assumption. Using a one dimensional equilibrium rocket engine code, the theoretical specific impulse at a mixture ratio of 1.5 is about

83 percent of the theoretical value at a mixture of 3 . Therefore, a specific impulse of 250 sec was assumed for a small engine using oxygen and methane produced from steam reforming of the waste stream.

Table VII summarizes the potential benefits that might be achieved on various missions if propellants from waste were available. For the Gateway mission, the propellants-from-waste could easily cover the yearly stationkeeping needs of the spacecraft. For a smaller Table VII. Potential benefits of processing waste into propellant.

\begin{tabular}{|l|c|c|c|c|c|c|}
\hline \multicolumn{1}{|c|}{ Mission } & Spacecraft & $\begin{array}{c}\text { Spacecraft } \\
\text { Mass, kg }\end{array}$ & TtG, m/s & TtSG, m/s & m/s & \\
\hline Gateway, Phase I & Core & 28,750 & 24.5 & 41.7 & $\sim 15$ & $\begin{array}{c}\text { Yearly station- } \\
\text { keeping }\end{array}$ \\
Gateway, Phase II & Core + MPLM & 45,573 & 30.8 & 52.5 & $\sim 15$ & Delta-V Requirement \\
\hline Robotic lunar & Mini-lander & $\begin{array}{c}200 \mathrm{~kg} \text { dry }+ \\
265 \mathrm{~kg} \text { payload }\end{array}$ & N/A* & $2800^{* *}$ & 2800 & L2 to surface \\
\hline Mars & DRA 5 & 196,000 & 12.8 & 21.8 & 25 & $\begin{array}{c}\text { mid-course } \\
\text { correction of entry- } \\
\text { corridor }\end{array}$ \\
\hline
\end{tabular}
spacecraft, such as a robotic mini-lander sent down to study the far side of the moon, the propellants-from-waste could enable landing a $200 \mathrm{~kg}$ payload on the lunar surface each year. Because the Mars mission spacecraft is so much more massive, the 
propellants-from-waste do not offer as much potential, being in the range of a mid-course correction or entrycorridor propulsive maneuver.

\section{Conclusion}

Over long-duration missions away from Earth, significant amounts of waste will be generated. Saving this waste to package and return to Earth or burn-up in orbit will no longer be an option and alternative solutions must be developed. One option that has been suggested is to dispose of the waste to space through a small airlock. An evaluation of physical reactions of the waste when exposed to a vacuum indicated that minimal water flashes to vapor upon initial exposure to the vacuum. Over time, approximately 20 percent of the total water in the waste will sublimate before the trash football is completely frozen. The initial hazard therefore of disposing of the waste to space is that these escaping volatiles can re-condense and contaminate the airlock surfaces or the airlock pump. Solid waste ejection using low velocity methods may be problematic for missions in a semi-stable orbit around the Earth-moon L2 point. While waste footballs released at select points in the orbit may intersect the lunar surface before having a chance to re-impact the spacecraft, the large number of waste footballs that will be generated indicate that another solution will be necessary. Several high-velocity disposal technologies were considered that were too large or too wasteful to recommend.

Processing the waste into useful gases was evaluated as an alternative to disposing of the solid waste to space. When considering the propellant and tankage required in low Earth orbit to push material out to L2, converting waste into useful gases can save 660 to $3300 \mathrm{~kg} / \mathrm{yr}$ in LEO. These gases could then be used to provide the yearly station-keeping needs at an L2 orbit, or if processed into oxygen and methane propellants, could be used to augment science exploration by enabling lunar mini landers to the far side of the moon.

\section{References}

${ }^{1}$ Smitherman, D., "Deep Space Habitat Configurations Based on International Space Station Systems, AES Habitation Project

${ }^{2}$ Drake, B.G., editor, "Human Exploration of Mars Design Reference Architecture 5.0," NASA/SP-2009-566, July, 2009.

${ }^{3}$ Ewert, M.K., and Broyan, J.L., "Mission Benefits Analysis of Logistics Reduction Technologies," AIAA-2013-3383, July, 2013.

${ }^{4}$ Hegde, U., Balasubramaniam, R., and Gokoglu, S., “Analysis of Water Extraction from Lunar Regolith,” AIAA-2012-0634, January, 2012.

${ }^{5}$ Andreas, E.L., "New Estimates for the Sublimation Rate for Ice on the Moon,” Icarus, vol 186, pp 24 - 30, 2006.

${ }^{6}$ Folta, D., Woodard, M., and Cosgrove, D., "Stationkeeping of the First Earth-Moon Libration Orbiters: The ARTEMIS Mission," AAS 11-515, August, 2011.

${ }^{7}$ Wheeler, J.T., “Alternate Apollo Missions - Libration Points,” NASA TM Report No. 53901, September, 1969.

"'L1 Lunar Lander Element Conceptual Design Report," NASA JSC Engineering Directorate internal report EX15-01-092, November, 2000.

${ }^{9}$ Suzuki, K., Matsumura, Y., and Doi, S., "Introduction of the Small Satellite Deployment Opportunity from JEM," NSS-03$0107,3^{\text {rd }}$ Nano-Satellite Symposium, December, 2011

${ }^{10}$ Staehle, R., Puig-Suari, J., Svitek, T., Friedman, L., and Blaney, D., "Interplanetary CubeSats: Some Missions Feasible Sooner than Expected," $1^{\text {st }}$ Interplanetary CubeSat Workshop, Cambridge, MA, 2012.

${ }^{11}$ Hintze, P., et. Al., "Trash to Supply Gas (TtSG) Project Overview," AIAA-2012-5254, September, 2012.

${ }^{12}$ Morren, W.E., Hay, S.S., Haag, T.W., and Sovey, J.S., "Preliminary Performance Characterizations of an Engineering Model Multipropellant Resistojet for Space Station Application,” NASA TM 100113, AIAA-87-2120, June, 1987. 